\title{
ИССЛЕДОВАНИЕ КАТАЛИТИЧЕСКИХ СВОЙСТВ И СТАБИЛЬНОСТИ ИММОБИЛИЗОВАННОИ ГЛЮКОЗООКСИДАЗЫ ИЗ PENICILLIUM VITALE
}

\author{
(Представил О. Эйзен)
}

Глюкозооксидаза (КФ 1.1.3.4.) катализирует реакцию окисления $\beta$-Д-глюкозы молекулярным кислородом:

$$
\beta \text {-Д-глюкоза }+\mathrm{O}_{2}+\mathrm{H}_{2} \mathrm{O} \rightarrow \text { глюконовая кислота }+\mathrm{H}_{2} \mathrm{O}_{2} \text {. }
$$

Кинетику этой реакции можно контролировать с помощью электрохимического датчика кислорода, измеряя концентрацию $\mathrm{O}_{2}$ в реакционной смеси. На базе этой же реакции можно создать также электрохимический датчик глюкозы. При этом глюкозооксидазу необходимо иммобилизировать на рабочей поверхности кислородного электрода. При этом в результате реакции (1) меняется эффективная концентрация определяемого датчиком кислорода в зависимости от концентрации глюкозы в растворе. Хотя решающее значение при создании такого электрохимического датчика глюкозы имеют способ иммобилизации и стабильность фермента на рабочей поверхности электрода, необходимо также учесть возможность изменения каталитических свойств глюкозооксидазы при ее ковалентной сшивке на полимерном носителе.

В настоящее время в СССР выпускается препарат глюкозооксидазы из Penicillium vitale. В целях выявления возможностей применения этого препарата для создания электрохимических датчиков глюкозы в настоящей работе исследовали возможности иммобилизации этого фермента на полиамиде и влияния такой процедуры на стабильность и каталитические свойства фермента.

\section{Экспериментальная часть}

В работе использовали препарат глюкозооксидазы из Pen. vitale отечественного производства. Растворы фермента готовили в $0,1 \mathrm{M}$ ацетатном или в $0,1 \mathrm{M}$ фосфатном буферах с рН 5,6 или 7,6 соответственно. Концентрация препарата от 1 до 4 мг/мл. Полученные растворы белка центрифугировали при $8000 \mathrm{~g}$ и $4{ }^{\circ} \mathrm{C}$ в течение 30 мин и затем использовали их для кинетических измерений, для иммобилизащии фермента на полиамидном волокне и в опытах проверки гомогенности и. отсутствия примесей каталазы в препарате.

Гельхроматографию препарата глюкозооксидазы проводили на колонке Sephacryl S-300 (16×800 мм, фирма «Pharmacia», Швеция), элюировали $0,1 \mathrm{M}$ фосфатным буфером с рН 7,6. Элюирование белка регистрировали с помощью адсорбиметра «Uvicord $\mathrm{S} »(\lambda=280$ нм $)$. Из элюата отбирали фракции по 1,5 мл и определяли по ним активность фермента. Для калибровки колонки использовали стандартные белки: каталазу, альбумин, овальбумин и цитохром из набора фирмы «Pharmacia».

Активность глюкозооксидазы измеряли с помощью электрохимического датчика кислорода в $0,1 \mathrm{M}$ ацетатном буфере с $\mathrm{pH} 5,6$ при $25^{\circ} \mathrm{C}$. 


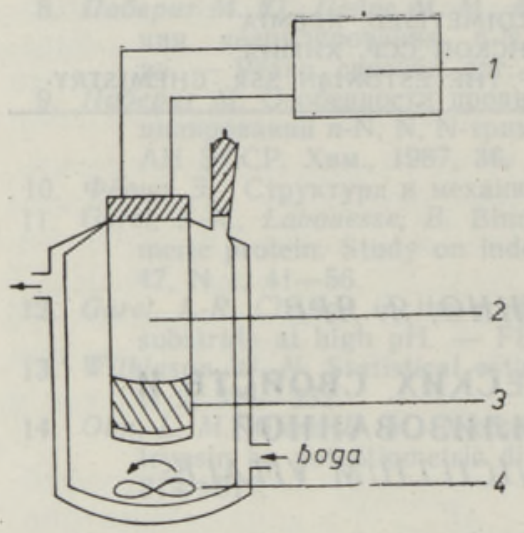

Рис. 1. Система измерения: 1 - регистрирующий прибор, 2 - кнслородный электрод, 3 - слой иммобилизованного фермента, 4 - мешалка.

Опыты проводили в закрытой термостатируемой ячейке, снабженной кислородным датчиком типа Кларка, при постоянном перемешивании раствора (рис. 1). Объем реакционной среды был 35 мл. Для получения насыщенного раствора кислорода через реакционную смесь пропускали в течение 45 мин очищенный от $\mathrm{CO}_{2}$ воздух. При необходимости варьирования концентрации кислорода в реакционной среде для вытеснения растворенного кислорода через реакционную среду пропускали аргон. Начальную концентрацию. кислорода определяли по показанию электрохимического датчика.

Для измерения начальной скорости окисления глюкозы или получения кинетической кривой для интегрального анализа в раствор глюкозы и кислорода в ацетатном буфере, предварительно термостатированный в реакционном сосуде, добавляли раствор фермента либо определенное количество иммобилизованного фермента. Самопишущий прибор регистрировал ход изменения концентрации кислорода в реакционной среде. Данные по начальной скорости окисления глюкозы обрабатывали в соответствии с уравнением

$$
v_{0}=\frac{k \cdot[S]}{K_{\mathrm{M}}+[S]},
$$

где $v_{0}-$ начальная скорость, $k$ - каталитическая константа скорости, $[S]$ - концентрация субстрата, $K_{M}$ - константа Михаэлиса.

После опыта датчик кислорода тщательно промывали ацетатным буфером и держали в течение 20 мин в $0,1 \mathrm{M}$ растворе $\mathrm{NaOH}$ для удаления сорбированных на пленке датчика белков. В опытах с иммобилизованным ферментом куски полиамидного носителя тщательно промывали буфером.

Для иммобилизации глюкозооксидазы на полиамиде носитель активировали диметилсульфатом при $60{ }^{\circ} \mathrm{C}$. Обработку полимера проводили в течение $2-5$ мин для выявления оптимальных условий активации полимера. Активированный полимер промывали при $0^{\circ} \mathrm{C}$ метанолом и $0,1 \mathrm{M}$ фосфатным буфером ( $\mathrm{pH} 7,6)$. Затем активированный носитель инкубировали при $4^{\circ} \mathrm{C}$ в растворе фермента концентрацией от 0,5 до 2 мг/мл. Время инкубации варьировали от 24 до 40 ч. Затем носитель промывали фосфатным буфером до полного удаления нековалентно сорбированного белка.

Стабильность иммобилизованного фермента измеряли при хранении препарата в ацетатном буфере при 4 и $20^{\circ} \mathrm{C}$, а также в сухом виде при тех же температурах. При этом в определенные моменты времени определяли активность связанного с носителем фермента, используя одинаковые условия реакции ( 25 м $M$ раствор глюкозы в ацетатном буфере с $\mathrm{pH} 5,6$, насыщенный кислородом при $\left.25^{\circ} \mathrm{C}\right)$. Данные обрабатывали в полулогарифмических координатах $\ln v$ и $t$, соответствующих кинетическому уравнению реакции первого порядка

$$
\ln v=\ln v_{0}-k_{\mathrm{IH}} \cdot t,
$$

\section{$+$}

где $v_{0}$ - начальная скорость окисления глюкозы в стандартных условиях, $k_{\text {нн }}$ - константа инактивации, $t$ - время. 


\section{Результаты и их обсуждение}

Использованная в работе глюкозооксидаза элюируется с колонки Sephacryl S-300 в виде одного симметричного пика, сопровождаемого некоторыми низкомолекулярными примесями $(\sim 12 \%)$, не обладающими ферментативной активностью (рис. 2). По данным гельхроматографии, глюкозооксидаза имеет молекулярную массу $155 \pm 5 \mathrm{kDa}$, что согласуется с приведенными в литературе данными для фермента из Pen. vitale [ $\left.{ }^{1}\right]$.

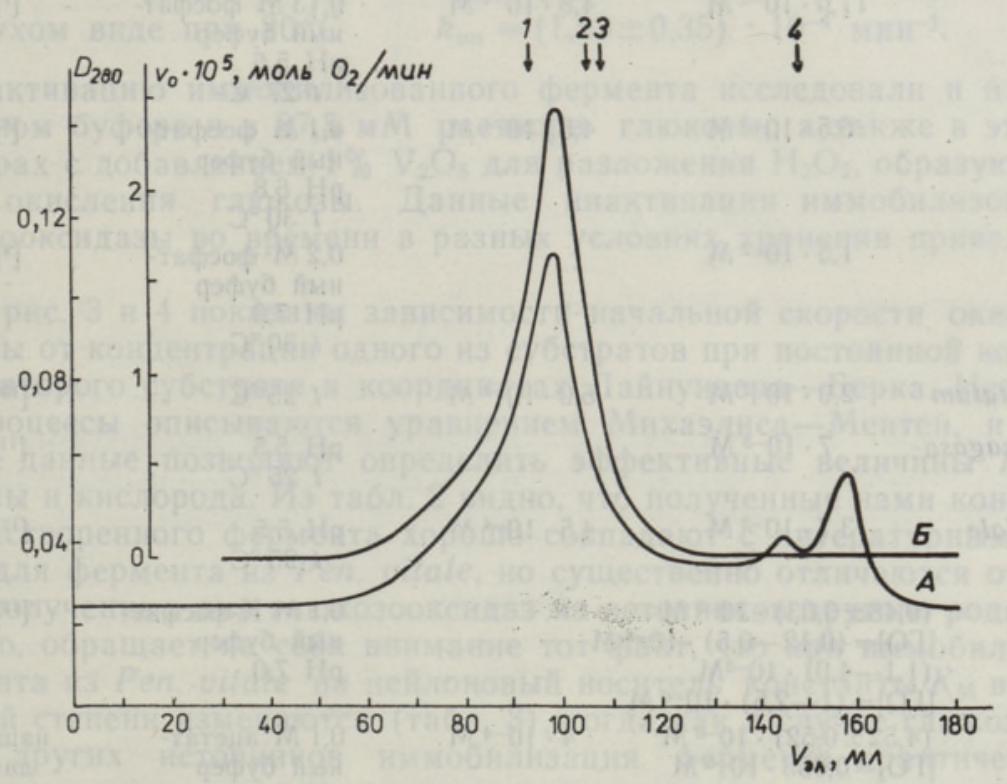

Рис. 2. Гельхроматография глюкозооксидазы на геле Sephacryl S-300. A. Концентрация белка определена спектрофотометрически $(\lambda=280$ нм). Б. Активность глюкозооксидазы определена электрохимически. Стрелками показаны объемы элюирования маркеров: 1 - каталаза (232 000), 2 - альбумин (67 000), 3 - овальбумин (43000), 4 - цитохром $(12300)$.

Для иммобилизации фермента на полиамидном волокне (нейлоне) оптимизировали время и температуру активации носителя, а также условия последующей процедуры сшивки фермента. Оказалось, что без ухудшения механических свойств носителя наибольшее количество фермента можно иммобилизировать после обработки полиамидного волокна в диметилсульфате при $60^{\circ} \mathrm{C}$ в течение 3 мин. После этого волокно необходимо обработать холодным метанолом [ㄹ. Последующую сшивку фермента на активированный носитель можно проводить при $4{ }^{\circ} \mathrm{C}$ в течение

Таблица 1

\section{Инактивация иммобилизованной глюкозооксидазы}

\section{Условия хранения}

в сухом виде при $4^{\circ} \mathrm{C}$

в сухом виде при $20^{\circ} \mathrm{C}$

в ащетатном буфере

в ащетатном буфере $+\mathrm{V}_{2} \mathrm{O}_{5}$

в 87,5 м М растворе глюкозы

в 87,5 м М растворе глюкозы $k^{\text {ин }} \cdot 10^{4}$, мин $^{-1}$

1,26

1,83

1,28

0,86

3,70

$\begin{array}{ll}+\mathrm{V}_{2} \mathrm{O}_{5} & 1,85\end{array}$ 
Каталитические свойства глюкозооксидаз (ГО) различного происхождения

\begin{tabular}{|c|c|c|c|c|}
\hline $\begin{array}{l}\text { Источник } \\
\text { фермента }\end{array}$ & $K_{M}^{\text {глюкоза }}$ & $K_{\mathrm{M}}^{\mathrm{O}_{2}}$ & Условия & $\begin{array}{l}\text { Источник } \\
\text { литературы }\end{array}$ \\
\hline Asp. niger & $6,02 \cdot 10^{-2} M$ & $5,37 \cdot 10^{-4} M$ & $\begin{array}{l}\mathrm{pH} 5,6 \\
t 30^{\circ} \mathrm{C}\end{array}$ & {$\left[{ }^{5}\right]$} \\
\hline$"$ & $2,26 \cdot 10^{-2} M$ & & $\begin{array}{rl}\mathrm{pH} & 5,5 \\
t & 25^{\circ} \mathrm{C}\end{array}$ & {$\left[{ }^{6}\right]$} \\
\hline$"$ & $11,0 \cdot 10^{-2} \mathrm{M}$ & $4,8 \cdot 10^{-4} M$ & $\begin{array}{l}0,13 \mathrm{M} \text { фосфат- } \\
\text { ный буфер } \\
\text { pH } 5,6 \\
t 27^{\circ} \mathrm{C}\end{array}$ & {$\left[{ }^{7}\right]$} \\
\hline$"$ & $6,5 \cdot 10^{-2} M$ & $4,5 \cdot 10^{-4} M$ & $\begin{array}{l}0,1 \mathrm{M} \text { фосфат- } \\
\text { ный буфер } \\
\mathrm{pH} 6,8 \\
t 30^{\circ} \mathrm{C}\end{array}$ & {$\left[{ }^{8}\right]$} \\
\hline 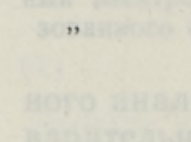 & $1,5 \cdot 10^{-2} \mathrm{M}$ & P. & $\begin{array}{l}0,2 \mathrm{M} \text { фосфат- } \\
\text { ный буфер } \\
\mathrm{pH} 7,0 \\
t 30^{\circ} \mathrm{C}\end{array}$ & {$\left[{ }^{9}\right]$} \\
\hline Pen. notatum & $2,9 \cdot 10^{-2} M$ & $5,0 \cdot 10^{-4} M$ & $t 25^{\circ} \mathrm{C}$ & {$\left[{ }^{10}\right]$} \\
\hline $\begin{array}{l}\text { Pen. amagast } \\
\text { kiense }\end{array}$ & a- $\quad 7 \cdot 10^{-3} \mathrm{M}$ & & $\begin{array}{l}\mathrm{pH} 5,5 \\
t 25^{\circ} \mathrm{C}\end{array}$ & ["1] \\
\hline Pen. vitale & $3,7 \cdot 10^{-3} \mathrm{M}$ & $4,5 \cdot 10^{-4} M$ & $\begin{array}{rl}\mathrm{pH} & 5,5 \\
t & 25^{\circ} \mathrm{C}\end{array}$ & {$\left[{ }^{12}\right]$} \\
\hline ! & $\begin{array}{l}(0,48 \pm 0,03) \cdot 10^{-3} M \\
{[\Gamma \mathrm{O}]=(0,12-0,5) \cdot 10^{-6} M} \\
(1,1-4,0) \cdot 10^{-3} M, \\
{[\text { [O }]=(1-2,5) \cdot 10^{-6} M}\end{array}$ & & $\begin{array}{l}0,1 \mathrm{M} \text { К-фосффат- } \\
\text { ный буфер } \\
\text { pH } 7,0\end{array}$ & {$\left[{ }^{13}\right]$} \\
\hline$"$ & $\begin{array}{l}(4,52 \pm 0,52) \cdot 10^{-3} \mathrm{M} \\
{[\text { ГO }]=0,053 \cdot 10^{-6} \mathrm{M}}\end{array}$ & $4 \cdot 10^{-4} M$ & $\begin{array}{l}0,1 \mathrm{M} \text { ацетат- } \\
\text { ный буфер } \\
\mathrm{pH} 5,6 \\
t 25^{\circ} \mathrm{C}\end{array}$ & $\begin{array}{c}\text { наши } \\
\text { дан- } \\
\text { ные }\end{array}$ \\
\hline
\end{tabular}

Каталитические свойства растворенных и

\begin{tabular}{l|l|l|l|}
\hline $\begin{array}{l}\text { Источник } \\
\text { фермента }\end{array}$ & $K_{M}^{\text {глюкоза }}$ & $K_{M}{ }^{{ }^{\mathrm{O}_{2}}}$ & Рсловия \\
\cline { 2 - 3 } & & Растворенный фермент \\
\hline
\end{tabular}

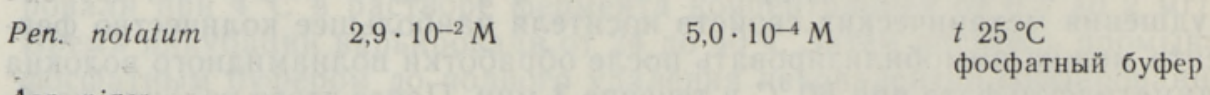

Asp. niger

$t 25^{\circ} \mathrm{C}$

фосфатный буфер

\begin{tabular}{|c|c|c|c|}
\hline Asp. niger & $7,21 \cdot 10^{-3} \mathrm{M}$ & & $\begin{array}{l}\mathrm{pH} 5,5 \\
0,1 \mathrm{M} \\
\text { ацетатный } \\
t 25^{\circ} \mathrm{C}\end{array}$ \\
\hline Pen. vitale & $(4,52 \pm 0,52) \cdot 10^{-3} M$ & $4 \cdot 10^{-4} \mathrm{M}$ & $\begin{array}{l}\text { pH } 5,6 \\
0,1 \mathrm{M} \\
\text { ацетатный } \\
t 25^{\circ} \mathrm{C}\end{array}$ \\
\hline
\end{tabular}


24 ч. При этом связанное с носителем количество фермента не растет при увеличении концентрации фермента в реакционной смеси от 1 до 2 мг/мл, а также при продлении времени инкубации носителя в растворе фермента. Активность иммобилизованного таким способом фермента уменьшается во времени экспоненциально. Этот процесс можно рассматривать как реакцию первого порядка, характеризуемую константой скорости $k_{\text {ин }}$. Скорость инактивации иммобилизованного фермента зависит от температуры и условий хранения, а также от метода иммобилизации фермента и характера носителя $\left[{ }^{3,4}\right]$. Из полученных данных можно вычислить константы инактивации иммобилизованного фермента:
в сухом виде при $4{ }^{\circ} \mathrm{C}$
$k_{\text {ин }}=(1,26 \pm 0,42) \cdot 10^{-4} \mathrm{Mин}^{-1}$,
в сухом виде при $20^{\circ} \mathrm{C}$
$k_{\text {нн }}=(1,83 \pm 0,35) \cdot 10^{-4} \mathrm{Mин}^{-1}$.

Инактивацию иммобилизованного фермента исследовали и в $0,1 \mathrm{M}$ ацетатном буфере и в 87,5 м $\mathrm{M}$ растворе глюкозы, а также в этих же растворах с добавлением $1 \% \mathrm{~V}_{2} \mathrm{O}_{5}$ для разложения $\mathrm{H}_{2} \mathrm{O}_{2}$, образующейся в ходе окисления глюкозы. Данные инактивации иммобилизованной глюкозооксидазы во времени в разных условиях хранения приведены в табл. 1.

На рис. 3 и 4 показаны зависимости начальной скорости окисления глюкозы от концентрации одного из субстратов при постоянной концентрации второго субстрата в координатах Лайнуивера-Берка. Исследуемые процессы описываются уравнением Михаэлиса-Ментен, и полученные данные позволяют определить эффективные величины $K_{M}$ для глюкозы и кислорода. Из табл. 2 видно, что полученные нами константы для растворенного фермента хорошо совпадают с литературными данными для фермента из Pen. vitale, но существенно отличаются от констант, полученных для глюкозооксидаз из источников другого рода. Кроме того, обращает на себя внимание тот факт, что при иммобилизации фермента из Pen. vitale на нейлоновый носитель константы $K_{M}$ в значительной степени изменяются (табл. 3), тогда как в случае глюкозооксидаз из других источников иммобилизация фермента практически не

Таблица 3

иммобилизованных глюкозооксидаз (ГО)

\begin{tabular}{|c|c|c|c|c|}
\hline \multicolumn{4}{|c|}{ Иммобилизованный фермент } & \multirow{2}{*}{$\begin{array}{c}\text { Источник } \\
\text { литера- } \\
\text { туры }\end{array}$} \\
\hline$K_{M}^{\text {глюкоза }}$ & $K_{M}{ }^{\mathrm{O}_{2}}$ & условия & метод иммобилизации & \\
\hline
\end{tabular}

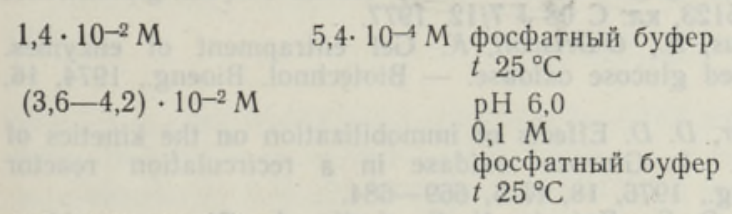

$(1,3-1,6) \cdot 10^{-2} \mathrm{M}$

$(0,5-1,2) \cdot 10^{-2} M$

$9,46 \cdot 10^{-2} M$

pH 5,5

$0,1 \mathrm{M}$ ацетатный буфер

$(2,72 \pm 0,44) \cdot 10^{-3} \mathrm{M}$

\section{$t 25^{\circ} \mathrm{C}$}

$\mathrm{pH} 5,6$

$0,1 \mathrm{M}$

ащетатный буфер $t 25^{\circ} \mathrm{C}$ $\left[{ }^{10}\right]$

Сферон 1000

ковалснтное связывание на электрод с помощью силана глутарого альдегида

с помощью аллиламина глутарого альдегида

с помощью альбумина глутарого альдегида

IO и каталаза на активированном угле

"

на нейлоновом волокне с наши помощью диметилсуль- данные фата 


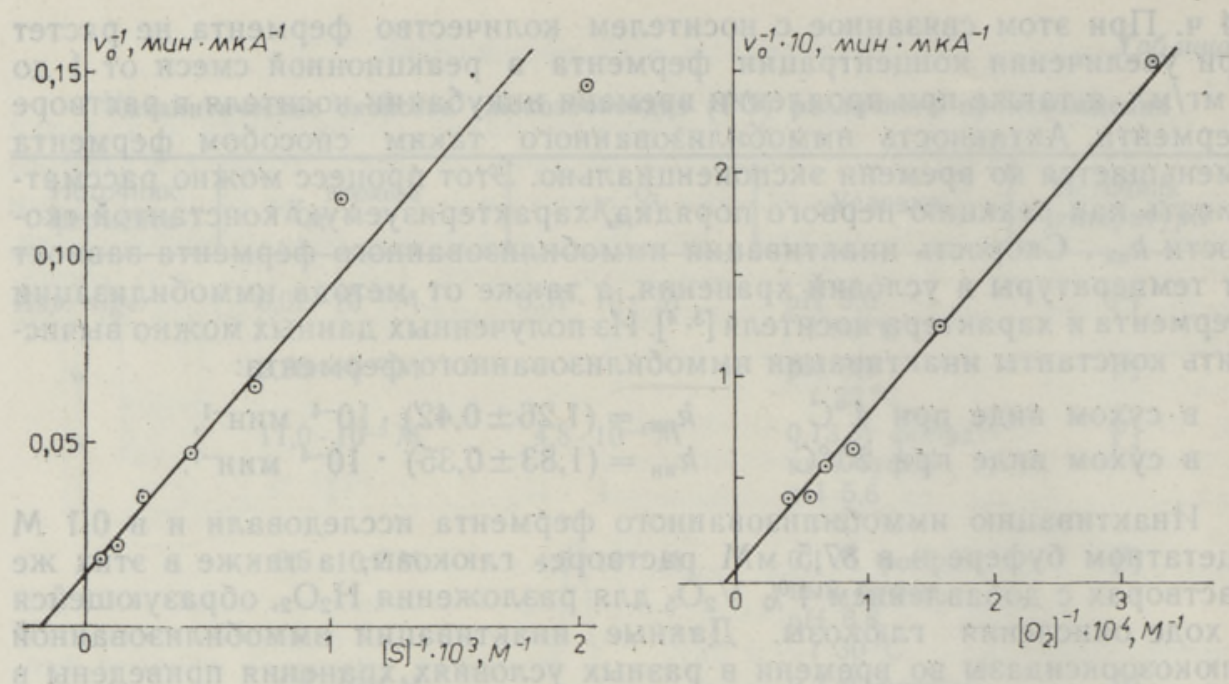

Рис. 3. Зависимость $v_{0}^{-1}=f\left([S]^{-1}\right)$ для глюкозы.

Рис. 4. Зависимость $v_{0}^{-1}=f\left([S]^{-1}\right)$ для кислорода.

влияет на константу Михаэлиса. Последний факт необходимо учитывать при создании электрохимического датчика, так как константа $K_{м}$ определяет пределы измеряемой концентрации глюкозы.

\section{Выводы}

1. С использованием метода активации полимера диметилсульфатом разработана методика иммобилизации глюкозооксидазы из Pen. vitale на полиамидном носителе и оптимизированы условия этой процедуры.

2. Исследованы каталитические свойства и стабильность иммобилизованной на полиамиде с помощью диметилсульфата глюкозооксидазы.

\section{Л ИТ Р Р А У Р А}

1. Абалихина Т. А., Морозкин А. Д., Богданов В. П., Каверзнева Е. Д. Состав и структура глюкозооксидазы из Penicillium vitale. - Биохимия, 1971, 36, № 1, $191-198$.

2. Патент Великобритании № 1485123 , кл. С 08 J 7/12, 1977.

3. Hinberg, I., Kapoulas, A., Korus, R., O'Driscoll, K. Gel entrapment of enzymes. Kinetic studies of immobilized glucose oxidase. - Biotechnol. Bioeng., 1974, 16, N 2, 159-168.

4. Ramachandran, K. B., Perlmutter, D. D. Effects of immobilization on the kinetics of enzyme-catalysed reactions. 1. Glucose oxidase in a recirculation reactor system. - Biotechnol. Bioeng., 1976, 18, N 5, 669-684.

5. Duke, F. R., Weibel, M., Page, D. S., Bulgrin, N. G., Luthy, J. Glucose oxidase mechanism. Enzyme activation by substrate. - J. Amer. Chem. Soc., 1969, 91, N 14, 3904-3909.

6. Weibel, M. K., Bright, H. J. Glucose oxidase mechanism. Interpretation of the $\mathrm{pH}$ dependence. - J. Biol. Chem., 1971, 249, N 9, 2734-2744.

7. Gibson, Q. H., Swoboda, B. E. P., Massey, V. Kinetics and mechanism of action of glucose oxidase. - J. Biol. Chem., 1964, 239, N 11, 3927-3934.

8. Malpiece, Y., Sharan, M., Barbotin, J., Personne, P., Thomas, D. A histochemical model dealing with an immobilized glucose oxidase-peroxidase system. J. Histochem. Cytochem., 1980, 28, N 9, 961-968.

9. Luca, C., Magearu, V., Virtosu, D., Ciucu, A. A fast method for the determination of catalase and glucose oxidase activities with an oxygen electrode. - Rev. roumaine biochim., $1983,20, \mathrm{~N} \mathrm{1,} 29-35$. 
10. Kühn, W., Kirstein, $D$., Mohr, $P$. Darstellung und Eigenschaiten trägerfixierter Glukoseoxydase. - Acta biol. et med. Germ., 1980, 39, N 11-12, 1121-1128.

11. Hayashi, S., Nakamura, S. Comparison of fungal glucose oxidases. Chemical, physicocheinical and immunological studies. - Biochim. Biophys. Acta, 1976, 438, N 1, $37-48$.

12. Акулова В. Ф., Вайткявичюс Р. К., Куртинайтене Б. С., Кулис Ю. Ю. Кинетика и стабильность глюкозооксидазы из Penicillium vitale. - Прикл. биохимия и микробиол., 1978, 14, № 3, 377-382.

13. Cenas, N. K., Kulys, J. J. Biocatalytic oxidation of glucose on the conductive charge transfer complexes. - Bioelectrochem. Bioenerg., 1981, 8, N 1, 103-113.

14. Castner, J. F., Wingard, L. B. Mass transport and reaction kinetic parametres determined electrochemically for immobilized glucose oxidase. - Biochem., 1984, 23, N 10, 2203-2210.

15. Tsukamoto, T., Nomura, H., Morita, S., Okada, J. Kinetic studies on the oxidation of glucose by immobilized glucose oxidase. - Chem. Pharm. Bull., 1983, 31, N $10,3377-3384$.

Тартуский государственный университет

\section{Поступила в редакцию}

$31 / \mathrm{X} 1986$

Toonika LIHU, Gerda RAIDARU, T. TENNO, J. JARV

\title{
IMMOBILISEERITUD PENICILLIUM VITALE GLUKOOSI OKSUDAASI KATALUOTILISTE OMADUSTE JA STABIILSUSE UURIMINE
}

On uuritud NSV Liidus toodetava glükoosi oksüdaasi immobiliseerimisvõimalusi nailonkandjale ning immobiliseeritud ensüümi stabiilsust erinevates tingimustes.

Lahustunud ja immobiliseeritud glükoosi oksüdaasi katalüütilisi omadusi on uuritud elektrokeemiliselt hapnikuanduri abil ning leitud, et glükoosi $K_{M}$ väärtus Pen. vitale glükoosi oksüdaasi poolt katalüüsitavas oksüdeerumisprotsessis väheneb ensüümi immobiliseerimisel. Seda on vaja arvestada ensüümelektroodide konstrueerimisel.

\author{
Toonika LIHU, Gerda RAIDARU, T. TENNO, J. JARV
}

\section{INVESTIGATION OF STABILITY AND CATALYTICAL PROPERTIES OF IMMOBILIZED GLUCOSE OXIDASE FROM PENICILLIUM VITALE}

The methods of immobilization of glucose oxidase, produced in the Soviet Union and the stability of the immobilized enzyme have been studied.

The catalytical properties of the soluble and immobilized glucose oxidase have been investigated electrochemically by making use of oxygen electrode. It was found that $K_{M}$ for glucose in the process of oxidation, catalyzed by glucose oxidase from Pen. vitale, decreases after the immobilization of the enzyme. This must be taken into account while constructing enzyme electrodes for determining glucose concentration in a solution. 